\title{
Maternal alcohol use during pregnancy in a general national population in South Africa
}

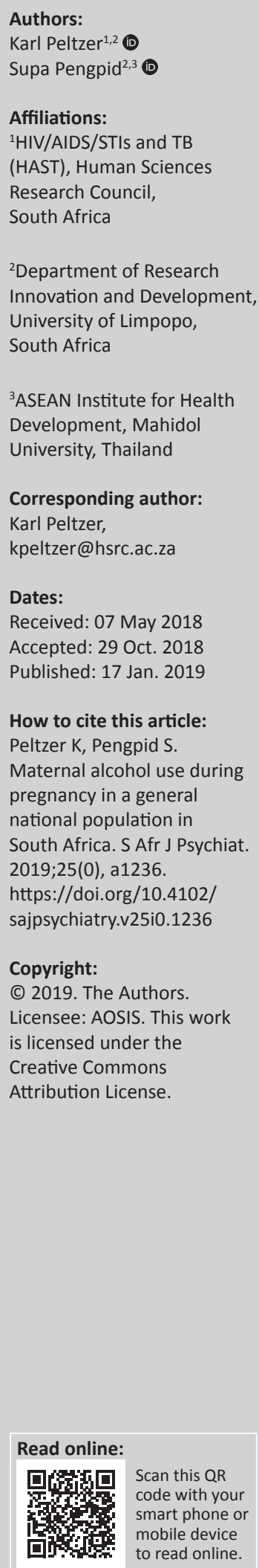

Objective: Alcohol use in pregnancy is linked with various negative health effects on the infant. The aim of this study was to examine the prevalence of maternal alcohol use during pregnancy and socio-demographic and health correlates.

Methods: Data of ever-pregnant women from the cross-sectional 'South African National Health and Nutrition Examination Survey (SANHANES-1) 2011-2012' were analysed. The sample included 5089 adolescents and adult women aged 15-55 years. They responded to questions on alcohol use, socio-demographic and health indicators.

Results: The results indicated that 3.7\% $(95.0 \%$ confidence interval $[C I]=3.1,4.5)$ of South African women had engaged in alcohol use during their pregnancy. In adjusted analysis, being mixed race, not employed, poor self-rated health status, ever been diagnosed with tuberculosis and having partial post-traumatic stress disorder were found to be associated with alcohol use during pregnancy.

Conclusions: The study findings suggest links between socio-demographic and health variables and prenatal alcohol use, which may have public health policy implications.

\section{Introduction}

Alcohol use in pregnancy is associated with negative health effects on the infant, such as lifelong disabilities, known as foetal alcohol spectrum disorders. ${ }^{1,2}$ Globally, in the general population, the estimated prevalence of alcohol use during pregnancy was $9.8 \%,{ }_{1}^{1}$ and in Southern Africa this figure was 6.6\%, including South Africa (13.2\%). ${ }^{3}$ These estimates are largely based on local surveys, which ranged (e.g. for South Africa) from $3.2 \%{ }^{4}$ and $6.5 \%{ }^{5}$ to $20.4 \%{ }^{6}$ and $42.8 \%{ }^{7}$ There is a lack of national data on alcohol use during pregnancy in South Africa.

Correlates of alcohol use during pregnancy include socio-demographic factors such as women of older age, having a higher income, being employed or unemployed, and ethnicity or population group (mixed race women). ${ }^{8,9,10}$ Moreover, smoking, ${ }^{11,12}$ traumatic experiences, ${ }^{13}$ exposure to violence $^{9}$ and poor physical and mental health ${ }^{9,14}$ have been identified as risk factors for maternal alcohol use during pregnancy. There is a lack of studies investigating physical and mental correlates of maternal alcohol use during pregnancy. Understanding these correlates could lead to the development of more effective prevention strategies for maternal alcohol use. ${ }^{9}$

The aim of this study was to examine the prevalence of maternal alcohol use during pregnancy and socio-demographic and health correlates.

\section{Methods}

\section{Sample and procedure}

The 'South African National Health and Nutrition Examination Survey (SANHANES-1)' is a cross-sectional and multi-stage population-based household survey conducted in 2011-2012; in more detail it is discussed elsewhere. ${ }^{15}$ A total of 25532 participants $(92.6 \%)$ completed the interview. ${ }^{15}$

\section{Measures}

Socio-demographic data included age, sex, employment status, population group, province and residential status.

Maternal alcohol use during pregnancy was measured through the following questions: (1) 'During pregnancy, did you ever have a drink containing alcohol?' (yes, no) and (2) 'during 
pregnancy, how many drinks containing alcohol did you have per day?' (Responses ranged from $1=1$ or 2 per week to $8=10$ or more per day. $)^{15}$ In addition, risky or hazardous drinking was assessed with the three-item 'Alcohol Use Disorders Identification Test-Consumption (AUDIT-C)'. Total scores range from 0 to 12 , with a score of 3 or more indicating risky or hazardous drinking or active alcohol use disorders ${ }^{16}$ (Cronbach's alpha 0.89).

Maternal tobacco use during pregnancy was assessed using the following question: 'during pregnancy, did you ever smoke tobacco or use any tobacco products?' (yes, no). In addition, current daily tobacco use was also assessed. ${ }^{16}$

Self-rated health was assessed using the following question: 'in general, how would you rate your health today?'15 Responses were dichotomised into as having 'good health' (1: very good, or 2: good) and 'poor health' ( 3: moderate, 4: bad or 5: very bad).

\section{Chronic conditions were measured with the question:}

has a doctor, nurse or health worker at a clinic or hospital told you that you have had any of the following conditions: high blood pressure, stroke, heart disease, heart attack or angina (chest pain), high blood cholesterol, high blood sugar or sugar diabetes? ${ }^{15}$

In addition, the participants were asked if they ever had been diagnosed with tuberculosis (yes or no). ${ }^{15}$

To assess the experience of trauma events, the participants were asked the following question:

Have you ever experienced any of the following events (14 events, e.g., 'severe automobile accidents' and 'learned about the sudden, unexpected death of a family member or a close friend')? (yes or no) ${ }^{15}$

Post-traumatic stress disorder (PTSD) was measured with the 'Davidson Trauma Scale (DTS)'. ${ }^{17}$ Partial PTSD was defined as having at least one PTSD symptom from each of the three PTSD symptom clusters ${ }^{18}$ (Cronbach's alpha 0.94).

Insomnia was measured with two items:

1. on the severity of nocturnal sleep problems: overall in the last 30 days, how much of a problem did you have with sleeping, such as falling asleep, waking up frequently during the night, or waking up too early in the morning?

2. and the severity of difficulty with daytime functioning overall in the last 30 days, how much of a problem did you have due to not feeling rested and refreshed during the day (e.g. feeling tired or not having energy)?

Response options ranged from $0=$ none to $4=$ extreme/ cannot do $^{19}$ (Cronbach's alpha 0.82). Insomnia symptoms were classified as having total scores of $\geq 4-8$.

Psychological distress was assessed with the 10-item Kessler questionnaire, ${ }^{20}$ which has been validated in South Africa ${ }^{21}$ (response options: $1=$ never to $5=$ all the time). Total scores of 30 or more indicate severe psychological distress ${ }^{20}$ (Cronbach's alpha 0.93).

\section{Data analysis}

Data were analysed using STATA software version 13.0 (Stata Corporation, College Station, TX, USA). Pearson's chi-square statistics were used to test the differences in proportions. Multivariable logistic regression was used to compute the odds ratios (with $95.0 \%$ confidence interval [CI]) to determine the associations between socio-demographic and health characteristics and maternal alcohol use during pregnancy. Independent variables found significant with the outcome (alcohol use during pregnancy) in bivariate analysis were subsequently included in the multivariable regression model. Current alcohol and tobacco use and tobacco use during pregnancy were excluded because of collinearity. No further collinearity was identified. All models were adjusted for the multi-stage sampling design.

\section{Ethical consideration}

Participants provided information on socio-demographic and health variables in face-to-face interviews after their informed consent was obtained. The current study sample is restricted to women who responded that they had ever been pregnant and were $15-55$ years old $(N=5089)$. The study was approved by the research ethics committee (REC) of the Human Sciences Research Council (REC 6/16/11/11).

\section{Results}

\section{Sample characteristics}

The total sample included 5089 women who had been pregnant and were 15 to 55 years old, with a median age of 35.0 years (interquartile range $[\mathrm{IQR}]=15$ ) from South Africa. The majority of participants $(80.0 \%)$ belonged to the black African population group, 39.6\% were employed and $63.7 \%$ were residing in urban areas. About one in five of the participants (23.3\%) rated their health as poor, $25.2 \%$ had one or more chronic conditions, $7.0 \%$ had ever been diagnosed with tuberculosis, $20.2 \%$ had experienced one or more traumatic events and $4.4 \%$ had a partial PTSD. In total, $7.4 \%$ of participants reported insomnia symptoms, $2.3 \%$ reported severe psychological distress, $4.8 \%$ told they had been using tobacco during their pregnancy, $9.1 \%$ told they were currently using tobacco daily and $11.9 \%$ were reported to be hazardous or harmful alcohol users.

Overall, 3.7\% had been using alcohol when they were pregnant: $8.4 \%$ among the mixed race population group, $7.3 \%$ in the Free State, 7.2\% in the Northern Cape and 6.1\% in the Western Cape province. In bivariate analysis, it was found that the prevalence of alcohol use during pregnancy was higher among unemployed than among employed participants, in participants with poorer self-rated health status, having ever been diagnosed with tuberculosis, having traumatic stress, partial PTSD and psychological distress. 
About one in four (26.1\%) of prenatal alcohol users had also been using tobacco during pregnancy, and $13.5 \%$ of prenatal alcohol users were current daily tobacco users and $19.7 \%$ were hazardous or harmful alcohol users (see Table 1).

Among women reporting alcohol use during pregnancy, $59.1 \%$ reported consuming alcohol once or twice per week, $23.7 \%$ reported three or four times per week, $7.8 \%$ reported five or six times per week, $5.4 \%$ stated once or twice per day and $4.1 \%$ stated three times or more per day.

\section{Associations with maternal alcohol use during pregnancy}

In adjusted analysis, being mixed race, unemployed, poor self-rated health status, having ever been diagnosed with TB and having partial PTSD were found to be associated with alcohol use during pregnancy (see Table 2).

\section{Discussion}

To our knowledge, this is the first population-based national study assessing the prevalence of maternal alcohol use during pregnancy in South Africa. The study found a prevalence of $3.7 \%$ of maternal alcohol use during pregnancy in South Africa, which is lower than previous estimates based on local surveys in South Africa (13.2\%), Southern Africa $(6.6 \%)$ and globally $(9.8 \%))^{1,3}$

Compared to this national survey in South Africa, the previously reported higher rate may be attributed to local surveys targeting higher risk groups such as the mixed race population groups. In addition, for this study the reference period for recalling alcohol use during pregnancy was the participants' whole reproductive period, while the other studies recalled alcohol use only during their current pregnancy. A shorter recall reference period may produce a higher prevalence of alcohol use. Furthermore, the study found that the proportion of pregnant women who engaged in binge drinking (three or more drinks per day) during pregnancy out of all pregnant women who consumed any amount of alcohol was $4.3 \%$, which seems similar to previous estimates for South Africa $(<5 \%)$ and lower than in 65 of 162 countries ( $>25.0 \%) .{ }^{22}$ Binge drinking during pregnancy is a direct cause of the foetal alcohol syndrome (FAS) and therefore is of particular concern..$^{22}$

In agreement with previous studies, $8,9,10,11,12,14$ this study found that demographic characteristics (e.g. being from the mixed race group and unemployed), tobacco use, poor self-rated health status, having had tuberculosis (TB) and partial PTSD increased the risk of maternal alcohol use during pregnancy. These risk groups should be specifically targeted for preconception alcohol prevention intervention. ${ }^{22}$ Furthermore, among the nine provinces in South Africa, the study found a particularly high prevalence of maternal alcohol use during pregnancy $(6.1 \%-7.3 \%)$ in three provinces (Free State, Northern Cape and Western Cape). Most of these
TABLE 1: Sample characteristics and weighted prevalence of alcohol use during pregnancy.

\begin{tabular}{|c|c|c|c|c|c|c|}
\hline \multirow[t]{2}{*}{ Variable } & \multicolumn{2}{|c|}{ Sample } & \multicolumn{3}{|c|}{$\begin{array}{l}\text { Alcohol use during } \\
\text { pregnancy }\end{array}$} & \multirow{2}{*}{$\begin{array}{l}\text { Chi-square } \\
p\end{array}$} \\
\hline & $N$ & $\%$ & $\%$ & $95 \%$ & $\mathrm{Cl}$ & \\
\hline \multicolumn{7}{|l|}{ Socio-demographic } \\
\hline \multicolumn{7}{|l|}{ Age (years) } \\
\hline All & 5089 & - & 3.7 & 3.1 & 4.5 & 0.113 \\
\hline $15-24$ & 862 & 15.0 & 5.2 & 3.6 & 7.5 & \\
\hline $25-34$ & 1451 & 32.9 & 3.2 & 2.3 & 4.5 & \\
\hline $35-55$ & 2776 & 52.2 & 3.6 & 2.8 & 4.6 & \\
\hline \multicolumn{7}{|l|}{ Population group } \\
\hline Black African & 3457 & 80.0 & 3.2 & 2.5 & 4.1 & 0.003 \\
\hline White people & 198 & 8.1 & 2.2 & 0.7 & 6.2 & \\
\hline Mixed race & 1036 & 9.8 & 8.4 & 6.2 & 11.4 & \\
\hline Indian or Asian & 343 & 2.1 & 4.7 & 1.2 & 16.6 & \\
\hline \multicolumn{7}{|l|}{ Province } \\
\hline Western Cape & 753 & 11.7 & 6.1 & 4.1 & 8.9 & $<0.001$ \\
\hline Eastern Cape & 524 & 11.3 & 3.2 & 1.9 & 5.6 & \\
\hline Northern Cape & 332 & 2.4 & 7.2 & 4.3 & 11.7 & \\
\hline Free State & 305 & 5.4 & 7.3 & 4.6 & 11.2 & \\
\hline KwaZulu-Natal & 802 & 18.5 & 3.3 & 2.0 & 5.5 & \\
\hline North West & 619 & 6.7 & 3.2 & 1.8 & 5.8 & \\
\hline Gauteng & 890 & 25.4 & 3.3 & 2.0 & 5.6 & \\
\hline Mpumalanga & 473 & 8.0 & 2.0 & 0.9 & 4.2 & \\
\hline Limpopo & 400 & 10.4 & 2.2 & 1.0 & 4.8 & \\
\hline \multicolumn{7}{|l|}{ Employment status } \\
\hline Unemployed & 3132 & 60.4 & 4.6 & 3.7 & 5.8 & 0.005 \\
\hline Employed & 1860 & 39.6 & 2.2 & 1.5 & 3.1 & \\
\hline \multicolumn{7}{|l|}{ Residence } \\
\hline Rural & 1656 & 36.3 & 2.9 & 2.0 & 4.0 & 0.170 \\
\hline Urban & 3132 & 63.7 & 4.2 & 3.3 & 5.3 & \\
\hline \multicolumn{7}{|l|}{ Health variables } \\
\hline \multicolumn{7}{|l|}{ Self-rated health status } \\
\hline Very good, good & 3856 & 76.7 & 3.0 & 2.4 & 3.9 & $<0.001$ \\
\hline Moderate, bad, very bad & 1173 & 23.3 & 5.8 & 4.3 & 7.8 & \\
\hline \multicolumn{7}{|l|}{ Chronic conditions } \\
\hline None & 3515 & 74.8 & 3.3 & 2.6 & 4.2 & 0.223 \\
\hline One or more & 1300 & 25.2 & 5.0 & 3.7 & 6.6 & \\
\hline \multicolumn{7}{|l|}{ Ever diagnosed with TB } \\
\hline No & 4636 & 93.0 & 3.4 & 2.8 & 4.3 & $<0.001$ \\
\hline Yes & 343 & 7.0 & 7.0 & 4.5 & 10.7 & \\
\hline \multicolumn{7}{|l|}{ Traumatic stress } \\
\hline None & 4021 & 79.8 & 3.2 & 2.5 & 4.0 & 0.009 \\
\hline One or more & 899 & 20.2 & 6.0 & 4.2 & 8.4 & \\
\hline \multicolumn{7}{|l|}{ PTSD } \\
\hline None & 4824 & 95.6 & 3.5 & 2.8 & 4.2 & $<0.001$ \\
\hline Partial & 197 & 4.4 & 9.6 & 6.0 & 15.1 & \\
\hline Insomnia & & & & & & \\
\hline $0-3$ & 4647 & 92.6 & 3.5 & 2.8 & 4.2 & 0.128 \\
\hline $4-8$ & 359 & 7.4 & 6.2 & 3.4 & 11.0 & \\
\hline Psychological distress & & & & & & \\
\hline$<30$ & 4808 & 97.7 & 3.5 & 2.9 & 4.3 & 0.006 \\
\hline 30 or more & 127 & 2.3 & 11.5 & 6.2 & 20.4 & \\
\hline Tobacco use during pregna & & & & & & \\
\hline No & 4638 & 95.2 & 2.7 & 2.1 & 3.4 & $<0.001$ \\
\hline Yes & 419 & 4.8 & 26.1 & 20.5 & 32.6 & \\
\hline Current tobacco use & & & & & & \\
\hline None $<$ daily & 4331 & 90.9 & 2.8 & 2.2 & 3.6 & $<0.001$ \\
\hline Daily & 660 & 9.1 & 13.5 & 10.3 & 17.4 & \\
\hline Current alcohol use & & & & & & \\
\hline Not hazardous or harmful & 4328 & 88.1 & 1.5 & 1.1 & 2.0 & $<0.001$ \\
\hline Hazardous or harmful & 679 & 11.9 & 19.7 & 15.8 & 24.3 & \\
\hline
\end{tabular}

$\mathrm{Cl}$, confidence interval; PTSD, post-traumatic stress disorder; TB, tuberculosis. 
TABLE 2: Multivariable logistic regression on alcohol use during pregnancy.

\begin{tabular}{|c|c|c|}
\hline Variable & $\operatorname{AOR}(95 \% \mathrm{Cl})$ & $p$ \\
\hline \multicolumn{3}{|l|}{ Socio-demographic } \\
\hline \multicolumn{3}{|l|}{ Population group } \\
\hline Black African & 1 (Reference) & \\
\hline White people & $1.64(0.71,3.78)$ & 0.246 \\
\hline Mixed race & $2.91(1.94,4.36)$ & $<0.001$ \\
\hline Indian or Asian & $1.21(0.34,4.31)$ & 0.763 \\
\hline \multicolumn{3}{|l|}{ Employment status } \\
\hline Employed & 1 (Reference) & \\
\hline Not formally employed & $1.78(1.15,2.74)$ & 0.009 \\
\hline \multicolumn{3}{|l|}{ Health variables } \\
\hline \multicolumn{3}{|l|}{ Self-rated health status } \\
\hline Very good, good & 1 (Reference) & \\
\hline Moderate, bad, very bad & $1.61(1.09,2.39)$ & 0.017 \\
\hline \multicolumn{3}{|l|}{ Ever diagnosed with TB } \\
\hline No & 1 (Reference) & \\
\hline Yes & $1.94(1.20,3.14)$ & 0.007 \\
\hline \multicolumn{3}{|l|}{ Traumatic stress } \\
\hline None & 1 (Reference) & \\
\hline One or more & $1.32(0.83,2.09)$ & 0.245 \\
\hline \multicolumn{3}{|l|}{ PTSD } \\
\hline None & 1 (Reference) & \\
\hline Partial & $2.02(1.12,3.66)$ & 0.020 \\
\hline \multicolumn{3}{|l|}{ Psychological distress } \\
\hline$<30$ & 1 (Reference) & \\
\hline 30 or more & $1.64(0.77,3.47)$ & 0.198 \\
\hline
\end{tabular}

AOR, adjusted odds ratio; $\mathrm{Cl}$, confidence interval; PTSD, post-traumatic stress disorder; TB, tuberculosis.

three provinces have the highest proportion of mixed race population groups in South Africa, emphasising the need to target the mixed race female population with preconception alcohol prevention intervention.

The co-occurrence between tobacco and alcohol use is well established. ${ }^{9}$ The fact that both substances (alcohol and tobacco) can have negative effects on the foetus; therefore, it is of great importance to consider both in the assessment and intervention strategies. ${ }^{9}$ The association found between poor mental health (partial PTSD, and psychological distress in bivariate analysis) and prenatal alcohol use may be explained by the comorbidity with common mental disorders such as anxiety and depression, 9 whereby self-medication with alcohol use may be one of the mechanisms. ${ }^{9}$ The association between TB and alcohol use in general has been established, with the latter being a risk factor for the former. ${ }^{23}$ As this study could not determine the direction of the relationships because of its cross-sectional nature, longitudinal studies are needed to clarify this.

\section{Study limitations}

The study variables of maternal alcohol use during pregnancy were assessed retrospectively over possibly long periods, which may have introduced a recall bias. The self-report of prenatal alcohol use is probably a large underestimate. ${ }^{24}$ Furthermore, the cross-sectional nature of the study limits our ability to establish causality.

\section{Conclusion}

This study found a prevalence rate of $3.7 \%$ of maternal alcohol use during pregnancy. The risk factors identified (being mixed race, unemployed, poor self-rated health status, having had TB and partial PTSD) can help in identifying appropriate interventions.

\section{Acknowledgements}

For providing the data set, the authors thank the 'Human Sciences Research Council. South African National Health and Nutrition Examination Survey (SANHANES-1) 2011-12: Adult Questionnaire - All provinces. [Data set]. SANHANES 2011-12 Adult Questionnaire. Version 1.0. Pretoria South Africa: Human Sciences Research Council [producer] 2012, Human Sciences Research Council [distributor] 2017. https:/ /doi.org/doi:10.14749/1494330158'.

\section{Competing interests}

The authors declare that they have no financial or personal relationships that may have inappropriately influenced in writing this article.

\section{Authors' contributions}

K.P. and S.P. designed the study. K.P. analysed the data and wrote the draft article. Both authors read and approved the final manuscript.

\section{References}

1. Popova S, Lange S, Probst C, Gmel G, Rehm J. Estimation of national, regional, and global prevalence of alcohol use during pregnancy and fetal alcohol syndrome: $A$ systematic review and meta-analysis. Lancet Glob Health. 2017;5(3):e290-e299. systematic review and meta-analysis. Lancet Glo
https://doi.org/10.1016/\$2214-109X(17)30021-9

2. World Health Organization (WHO). Prevention of harm caused by alcoho exposure in pregnancy, 2016 [homepage on the Internet]. [cited 2018 May 10]. Available from: http://www.euro.who.int/_data/assets/pdf_file/0005/318074/ Available from: http://www.euro.who.int/_data/assets/
Prevention-harm-caused-alcohol-exposure-pregnancy.pdf

3. Popova $S$, Lange $S$, Probst $C$, et al. Actual and predicted prevalence of alcohol consumption during pregnancy in the WHO African Region. Trop Med Int Health. 2016;21(10):1209-1239. https://doi.org/10.1111/tmi.12755

4. Erasmus I, Nicolaou E, van Gelderen CJ, Nicolaides KH. Cervical length at 23 weeks' gestation-relation to demographic characteristics and previous obstetric history in South African women. S Afr Med J. 2005;95:691-695.

5. Matseke G, Peltzer K, Mlambo G. Partner violence and associated factors among pregnant women in Nkangala district, Mpumalanga. S Afr J Obstet Gynaecol. 2012;18:77-81.

6. Vythilingum B, Roos A, Faure S, Geerts L, Stein D. Risk factors for substance use in pregnant women in South Africa. S Afr Med J. 2012;102:851-854. https://doi. org/10.7196/SAMJ.5019

7. Croxford JA, Viljoen D. Alcohol consumption by pregnant women in the Western Cape. S Afr Med J. 1999;89:962-965.

8. Lange S, Quere M, Shield K, Rehm J, Popova S. Alcohol use and self-perceived mental health status among pregnant and breastfeeding women in Canada: A secondary data analysis. BJOG. 2016;123(6):900-909. https://doi. secondary data analysis.
org/10.1111/1471-0528.13525

9. Skagerstróm J, Chang G, Nilsen P. Predictors of drinking during pregnancy: A systematic review. J Womens Health (Larchmt). 2011;20(6):901-913. https://doi. org/10.1089/jwh.2010.2216

10. Petersen-Williams $P$, Mathews $C$, Jordaan E, Parry CDH. Predictors of alcohol use during pregnancy among women attending midwife obstetric units in the Cape Metropole, South Africa. Subst Use Misuse. 2017;8:1-11. https://doi.org/10.1080/ 10826084.2017.1408654

11. Dumas A, Toutain S, Simmat-Durand L. Alcohol use during pregnancy or breastfeeding: A national survey in France. J Womens Health. 2017;26(7):798805. https://doi.org/10.1089/jwh.2016.6130

12. O'Keeffe LM, Kearney PM, McCarthy FP, et al. Prevalence and predictors of alcohol use during pregnancy: Findings from international multicentre cohort studies. BMJ Open. 2015;5(7):e006323. https://doi.org/10.1136/bmjopen-2014-006323

13. Choi KW, Abler LA, Watt MH, et al. Drinking before and after pregnancy recognition among South African women: The moderating role of traumatic experiences. BMC Pregnancy Childbirth. 2014;14:97. https://doi.org/10.1186/1471-2393-14-97

14. Oh S, Reingle Gonzalez JM, Salas-Wright CP, Vaughn MG, DiNitto DM. Prevalence and correlates of alcohol and tobacco use among pregnant women in the 
United States: Evidence from the NSDUH 2005-2014. Prev Med. 2017;97:93-99. https://doi.org/10.1016/j.ypmed.2017.01.006

15. Shisana O, Labadarios D, Rehle T, et al. South African National Health and Nutrition Examination Survey (SANHANES-1) [homepage on the Internet]. Cape Town: HSRC Press; 2013. [cited 2018 Sep 10]. Available from: http://www.hsrc.ac.za/uploads/ pageNews/72/SANHANES-launch $\% 20$ edition $\% 20$ (online $\% 20$ version).pdf

16. Bush K, Kivlahan DR, McDonell MB, Fihn SD, Bradley KA. The AUDIT alcoho consumption questions (AUDIT-C): An effective brief screening test for problem drinking. Ambulatory Care Quality Improvement Project (ACQUIP). Alcohol Use Disorders Identification Test. Arch Intern Med. 1998;158:1789-1795. https://doi. org/10.1001/archinte.158.16.1789

17. Davidson JR, Book SW, Colket JT, et al. Assessment of a new self-rating scale for post-traumatic stress disorder. Psychol Med. 1997;27(1):153-160. https://doi. org/10.1017/S0033291796004229

18. Breslau N, Lucia VC, Davis GC. Partial PTSD versus full PTSD: An empirical examination of associated impairment. Psychol Med. 2004;34(7):1205-1214.

19. Stranges S, Tigbe W, Gómez-Olivé FX, Thorogood M, Kandala NB. Sleep problems: An emerging global epidemic? Findings from the INDEPTH WHO-SAGE study among more than 40,000 older adults from 8 countries across Africa and Asia. Sleep. 2012;35(8):1173-1181. https://doi.org/10.5665/sleep.2012
20. Kessler RC, Andrews G, Colpe LJ, et al. Short screening scales to monitor population prevalences and trends in non-specific psychological distress. Psychol Med. 2002;32(6):959-976. https://doi.org/10.1017/S00332917 02006074

21. Andersen LS, Grimsrud A, Myer L, Williams DR, Stein DJ, Seedat S. The psychometric properties of the $\mathrm{K} 10$ and $\mathrm{K} 6$ scales in screening for mood and anxiety disorders in the South African Stress and Health study. Int J Meth Psychiatr Res. 2011;20(4):215-223. https://doi.org/10.1002/mpr.351

22. Lange S, Probst C, Rehm J, Popova S. Prevalence of binge drinking during pregnancy by country and World Health Organization region: Systematic review and meta-analysis. Reprod Toxicol. 2017;73:214-221. https://doi.org/10.1016/j. reprotox.2017.08.004

23. Imtiaz S, Shield KD, Roerecke M, Samokhvalov AV, Lönnroth K, Rehm J. Alcohol consumption as a risk factor for tuberculosis: Meta-analyses and burden of disease. Eur Respir J. 2017;50(1):1700216. https://doi.org/10.1183/13993003.00216-2017

24. Lange S, Shield K, Koren G, Rehm J, Popova S. A comparison of the prevalence of prenatal alcohol exposure obtained via maternal self-reports versus meconium testing: A systematic literature review and meta-analysis. BMC Pregnancy Childbirth. 2014;14:127. https://doi.org/10.1186/1471-2393-14-127 